\title{
Effects of Particle Size and Type of Alumina on the Morphology and Photoluminescence Properties of $\mathrm{Sr}_{4} \mathrm{Al}_{14} \mathrm{O}_{25}: \mathrm{Eu}^{2+} / \mathrm{Dy}^{3+}$ Phosphor
}

\author{
Hom Nath Luitel, Takanori Watari, Toshio Torikai, and Mitsunori Yada \\ Department of Applied Chemistry, Faculty of Science and Engineering, Saga University, Honjo-1 Saga 840 8502, Japan
}

Correspondence should be addressed to Takanori Watari, watarit@cc.saga-u.ac.jp

Received 18 November 2008; Accepted 28 January 2009

Recommended by Kevin Knowles

$\mathrm{Sr}_{4} \mathrm{Al}_{14} \mathrm{O}_{25}: \mathrm{Eu}^{2+} / \mathrm{Dy}^{3+}$ phosphor with high luminescence intensity and long afterglow duration was synthesized using $1.0 \mu \mathrm{m}(\alpha)$, $0.1 \mu \mathrm{m}(\alpha)$, and $0.05 \mu \mathrm{m}(\gamma)$ particle sizes of $\mathrm{Al}_{2} \mathrm{O}_{3}$. SEM observation results showed that spike-like thin particles were formed when $0.05 \mu \mathrm{m} \gamma-\mathrm{Al}_{2} \mathrm{O}_{3}$ was used as raw material. Hexagonal thick particles were observed when $0.1 \mu \mathrm{m} \alpha-\mathrm{Al}_{2} \mathrm{O}_{3}$ was used. But irregular, thin particles were observed while using $1 \mu \mathrm{m} \alpha-\mathrm{Al}_{2} \mathrm{O}_{3}$. Photoluminescence measurements showed that both the initial intensity and the long persistency were much higher for the phosphor prepared using $\gamma-\mathrm{Al}_{2} \mathrm{O}_{3}$ of $0.05 \mu \mathrm{m}$ particle size.

Copyright ( $) 2009$ Hom Nath Luitel et al. This is an open access article distributed under the Creative Commons Attribution License, which permits unrestricted use, distribution, and reproduction in any medium, provided the original work is properly cited.

\section{Introduction}

Of the phosphors, the alkali earth aluminates containing rare earth ions are functional inorganic materials with strong luminescence in blue to red regions [1-3]. These materials are widely used in various fields; to highlight a few, one may include emergency signs, low level lightening escape systems, military applications, textile fibers, lightening apparatus, exit signboards, and many more [4]. These materials, due to better safe, chemical stability, excellent photo resistance, very high brightness, and long-lasting afterglow with no radio active radiations [5], form the important materials in various ceramics industries [6].

In recent years, $\mathrm{SrAl}_{2} \mathrm{O}_{4}$ and $\mathrm{Sr}_{4} \mathrm{Al}_{14} \mathrm{O}_{25}$ doped with $\mathrm{Eu}^{2+}$ and $\mathrm{Dy}^{3+}$ have been regarded as an excellent phosphor and attracted the researcher's interest. For the improvement of phosphorescence, many researches have been focused on regarding additives, molar ratio of constituents, and the preparation methods [6-8]. It was found that the shape and size of phosphor particles play important role for the phosphorescence properties. When the particle size reaches the nanoscale, new properties are appeared like the blue shift of emission intensity [9]. If the phosphor particles are regular and flat plate-like, they are expected to give a better light absorption and form a dense compact by their orientation, resulting in higher phosphorescence intensity. The shape and size of the phosphor particles may depend on the crystal type and particle size of the starting materials as well as the method of preparation. This letter reports the effect of raw $\mathrm{Al}_{2} \mathrm{O}_{3}$ type and size on the formation of regular particles for the higher luminescence intensity of $\mathrm{Sr}_{4} \mathrm{Al}_{14} \mathrm{O}_{25}: \mathrm{Eu}^{2+}, \mathrm{Dy}^{3+}$ phosphor.

\section{Experimental}

Strontium aluminates doped with $\mathrm{Eu}^{2+}$ and $\mathrm{Dy}^{3+}$ $\left(\mathrm{Sr}_{4} \mathrm{Al}_{14} \mathrm{O}_{25}: \mathrm{Eu}^{2+} / \mathrm{Dy}^{3+}\right)$ were prepared by the reaction between strontium carbonate $\left(\mathrm{SrCO}_{3}\right.$; Sigma-Aldrich, Inc., Mo, USA), aluminum oxide $\left(\mathrm{Al}_{2} \mathrm{O}_{3}\right.$ Sigma-Aldrich, Inc., Mo, USA), europium oxide $\left(\mathrm{Eu}_{2} \mathrm{O}_{3}\right.$; Sigma-Aldrich, Inc., Mo, USA, $99.9+\%)$, and dysprosium oxide $\left(\mathrm{Dy}_{2} \mathrm{O}_{3}\right.$; SigmaAldrich, Inc., Mo, USA, 99.9+ \%). Boric acid $\left(\mathrm{H}_{3} \mathrm{BO}_{3}\right.$; Katayama Chemicals, Japan) was used as a flux. The powders were mixed according to the nominal composition of $4 \mathrm{SrCO}_{3}+7 \mathrm{Al}_{2} \mathrm{O}_{3}+0.4 \mathrm{~B}\left(\right.$ as $\left.\mathrm{H}_{3} \mathrm{BO}_{3}\right)+4$ at $\%$ Eu and 8 at $\%$ Dy. In this work, different particle size alumina of $\gamma$ and $\alpha$ types $(0.05 \mu \mathrm{m} \gamma$-type, $0.1 \mu \mathrm{m}$, and $1.0 \mu \mathrm{m}, \alpha$-type $)$ were 
used to reveal the effect of raw alumina powder. The mixing was performed thoroughly by mortal and pestle with the help of ethanol. Pellets were prepared and preheated in air atmosphere at $1000^{\circ} \mathrm{C}$ for 4 hours, pulverized and then heated at $1300^{\circ} \mathrm{C}$ for 5 hours in a reducing atmosphere of $\mathrm{H}_{2} / \mathrm{N}_{2}=1 / 9$.

Phase identification was carried out using a Shimadzu XRD-6300 instrument with $\mathrm{CuK} \alpha$ radiation at room temperature. Scanning electron microscopy (SEM) observations were carried out using a JEOLJSM-5510LV instrument. Photoluminescence (PL) spectra were measured using USB 4000 UV-VIS miniature fiber optic spectrometer (Ocean Optics, Fla, USA ). The decay curves were obtained at room temperature using a brightness meter (Konica Minolta LS100 ). Before decay curves measurement, the samples were exposed to standard $60 \mathrm{~W}$ xenon lamps for 25 minutes. All measurements were carried out at room temperature.

\section{Results and Discussion}

The X-ray diffraction patterns of the specimens prepared from the different particle sizes and crystal types of $\mathrm{Al}_{2} \mathrm{O}_{3}$ were almost the same as shown in Figure 1. The same $\mathrm{Sr}_{4} \mathrm{Al}_{14} \mathrm{O}_{25}$ phase was formed (except very small impurities of $\mathrm{SrAl}_{4} \mathrm{O}_{7}$ phase in all three samples as in Figure 1) which was confirmed when compared with standard JCPDS card data (52-1876). This result indicates that the reaction conditions under this work were enough for the formation of $\mathrm{Sr}_{4} \mathrm{Al}_{14} \mathrm{O}_{25}$ phase. Also the change of particle size and crystal type of starting $\mathrm{Al}_{2} \mathrm{O}_{3}$ did not affect the phase formation.

Figure 2 shows the SEM microstructure of the three samples prepared using $\mathrm{Al}_{2} \mathrm{O}_{3}$ of different particle sizes: (a) $0.05 \mu \mathrm{m}(\gamma)$, (b) $0.1 \mu \mathrm{m}(\alpha)$, and (c) $1.0 \mu \mathrm{m}(\alpha)$. Although the same phase was observed as in XRD observations, their microstructures were quite different. When $\gamma-\mathrm{Al}_{2} \mathrm{O}_{3}$ of smaller particle size was used as precursor powder, a ball-like microstructure composed of spikes or elongated plates was observed. The average size of the plate particle was roughly $1 \mu \mathrm{m}$ long, $0.2 \mu \mathrm{m}$ wide, and $20 \mathrm{~nm}$ thick. Due to the formation of regular and smaller particles, these small plates overlapped with each other, forming compact ball-like structure. The size of the ball was about $3 \mu \mathrm{m}$ in diameter. When $0.1 \mu \mathrm{m} \alpha-\mathrm{Al}_{2} \mathrm{O}_{3}$ was used, irregular porous microstructure composed of bigger and thicker hexagonal plates with $1 \mu \mathrm{m}$ long, $0.75 \mu \mathrm{m}$ wide, and $0.5 \mu \mathrm{m}$ thick was formed as in Figure 2(b). These plates connected with each other and form walls, making the spongy structure. While, using $\alpha-\mathrm{Al}_{2} \mathrm{O}_{3}$ of $1.0 \mu \mathrm{m}$ particle size, much bigger but thinner, irregular flat plates of $3 \mu \mathrm{m}$ long $2 \mu \mathrm{m}$ wide, and $30 \mathrm{~nm}$ thick were observed as in Figure 2(c). Due to the high aspect ratio of the irregular plates, porous microstructure was formed. The porous microstructure was further supported by the density of the prepared pellets that decreased on increasing the particle size of raw alumina powder and also the phosphor particles $\left(0.05 \mu-1.909 \mathrm{~g} / \mathrm{cm}^{3}>\right.$ $\left.0.1 \mu-1.87 \mathrm{~g} / \mathrm{cm}^{3}>1.0 \mu-1.803 \mathrm{~g} / \mathrm{cm}^{3}\right)$. The particle shape dependency according to the starting alumina powder may be explained on the basis of dissolution and precipitation

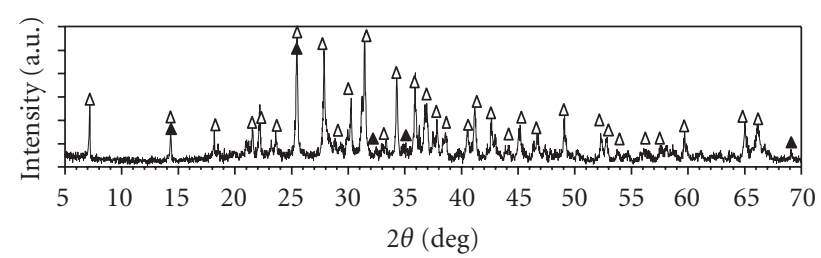

(a) $0.05 \mu \mathrm{m} \mathrm{Al} \mathrm{O}_{3}$

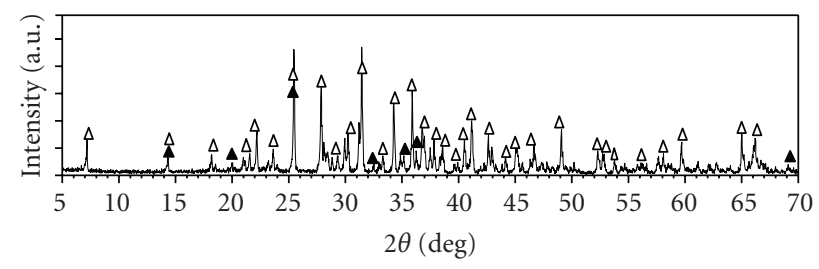

(b) $0.1 \mu \mathrm{m} \mathrm{Al} \mathrm{O}_{3}$

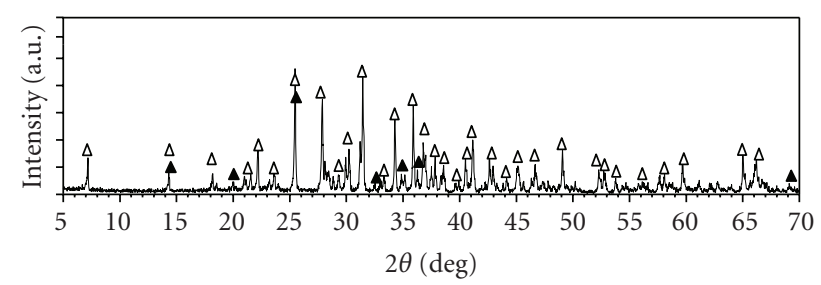

$\Delta \mathrm{Sr}_{4} \mathrm{Al}_{14} \mathrm{O}_{25}$

$\Delta \mathrm{SrAl}_{4} \mathrm{O}_{7}$

(c) $1.0 \mu \mathrm{m} \mathrm{Al}{ }_{2} \mathrm{O}_{3}$

FIGURE 1: X-ray diffraction pattern of $\mathrm{Sr}_{4} \mathrm{Al}_{14} \mathrm{O}_{25}: \mathrm{Eu}^{2+} / \mathrm{Dy}^{3+}$ phosphor prepared using (a) $0.05 \mu \mathrm{m} ; \gamma-\mathrm{Al}_{2} \mathrm{O}_{3}$, (b) $0.1 \mu \mathrm{m} ; \alpha-\mathrm{Al}_{2} \mathrm{O}_{3}$, and (c) $1.0 \mu \mathrm{m} ; \alpha-\mathrm{Al}_{2} \mathrm{O}_{3}$.

mechanisms [10]. The detail mechanism for the explanation of different shapes according to the starting material is under progress.

Figure 3 shows the excitation and emission spectra of $\mathrm{Sr}_{4} \mathrm{Al}_{14} \mathrm{O}_{25}: \mathrm{Eu}^{2+} / \mathrm{Dy}^{3+}$ phosphor prepared using $0.05 \mu \mathrm{m}$, $0.1 \mu \mathrm{m}$, and $1.0 \mu \mathrm{m} \mathrm{Al} \mathrm{O}_{2} \mathrm{O}_{3}$ as starting materials. All samples prepared from these three types of $\mathrm{Al}_{2} \mathrm{O}_{3}$ were excitated by the light of wavelength ranging from 220 to $440 \mathrm{~nm}$. These samples gave the similar emission spectra with peaks at $\sim 500 \mathrm{~nm}$ showing blue-green color. However, there was a small blue shift in the case of phosphor prepared using $0.05 \mu \mathrm{Al}_{2} \mathrm{O}_{3}$. It is obvious that the decrease in particle size increases the surface energy, which results in the distortion of atomic structure around the $\mathrm{Eu}^{2+}$, and consequently, the blue shift in the emission peak is observed [9]. The emission intensity of these phosphors, however, varied drastically according to the used raw alumina powder as shown in the inserted graph in Figure 4. The initial emission intensities of the products from $0.05 \mu \mathrm{m}, 0.1 \mu \mathrm{m}$, and $1.0 \mu \mathrm{m} \mathrm{Al} \mathrm{O}_{3}$ were $2316,137,9$ and $1025 \mathrm{mcd} \cdot \mathrm{m}^{-2}$, respectively. The emission intensity increased with the decreasing of $\mathrm{Al}_{2} \mathrm{O}_{3}$ particle size and became the highest for the phosphor prepared using $0.05 \mu \mathrm{m} \mathrm{Al} \mathrm{Al}_{2} \mathrm{O}_{3}$. The decrease in phosphorescence intensity might be due to the formation of bigger particles with much porous microstructure on increasing the $\mathrm{Al}_{2} \mathrm{O}_{3}$ particle 


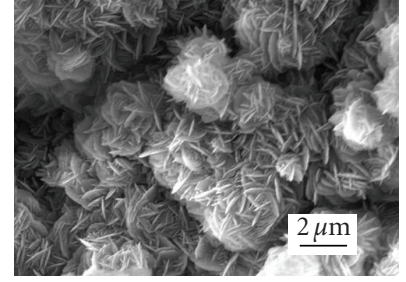

(a)

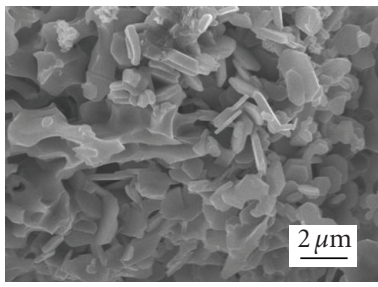

(b)

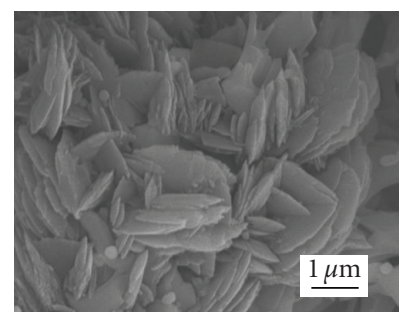

(c)

Figure 2: SEM microstructure of $\mathrm{Sr}_{4} \mathrm{Al}_{14} \mathrm{O}_{25}: \mathrm{Eu}^{2+} / \mathrm{Dy}^{3+}$ phosphor prepared using (a) $0.05 \mu \mathrm{m} ; \gamma-\mathrm{Al}_{2} \mathrm{O}_{3}$, (b) $0.1 \mu \mathrm{m} ; \alpha-\mathrm{Al}_{2} \mathrm{O}_{3}$, and (c) $1.0 \mu \mathrm{m} ; \alpha-\mathrm{Al}_{2} \mathrm{O}_{3}$.

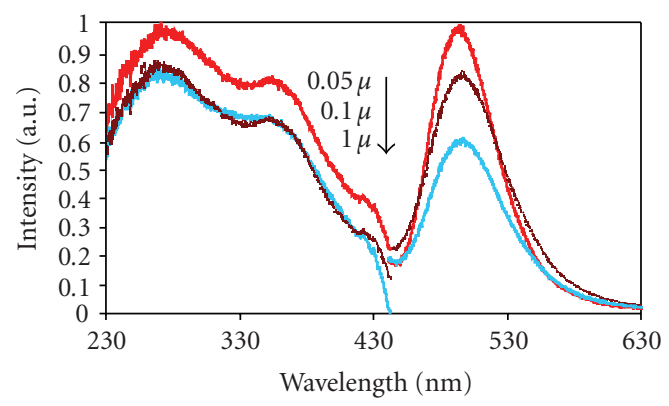

Figure 3: Excitation (normalized) and emission spectra of $\mathrm{Sr}_{4} \mathrm{Al}_{14} \mathrm{O}_{25}: \mathrm{Eu}^{2+} / \mathrm{Dy}^{3+}$ phosphor using (a) $0.05 \mu \mathrm{m} ; \gamma-\mathrm{Al}_{2} \mathrm{O}_{3}$, (b) $0.1 \mu \mathrm{m} ; \alpha-\mathrm{Al}_{2} \mathrm{O}_{3}$, and (c) $1.0 \mu \mathrm{m} ; \alpha-\mathrm{Al}_{2} \mathrm{O}_{3}$.

size as explained in the SEM microstructure observations. Obviously, as the packing density decreases, the volume content of the phosphor decreases leading to the decrease of the emission intensity of the phosphor.

Figure 4 shows the change in the afterglow emission intensity of the phosphor products with time. The afterglow intensity was decreased by $>1 / 100$ th of the initial intensity within 1 hour. The afterglow emission intensity and duration were higher for the phosphor prepared using $0.05 \mu \mathrm{m} \gamma-\mathrm{Al}_{2} \mathrm{O}_{3}$, and its afterglow duration over the value

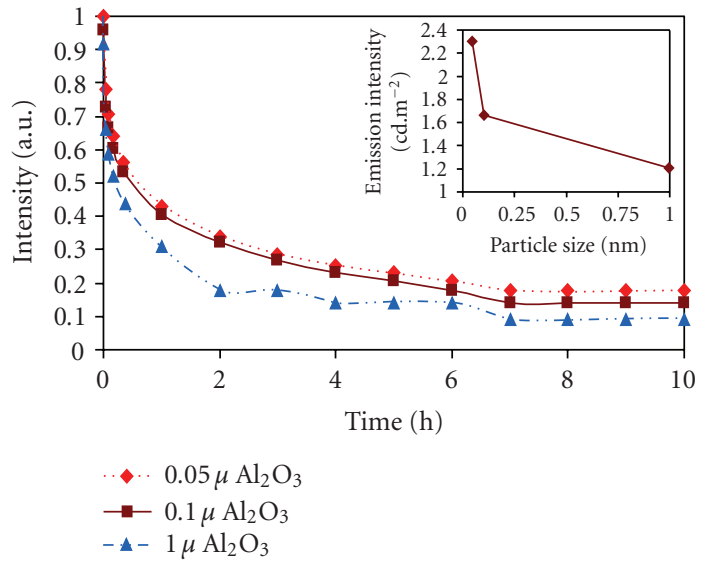

Figure 4: Effect of $\mathrm{Al}_{2} \mathrm{O}_{3}$ particle size on the photoluminescence properties of $\mathrm{Sr}_{4} \mathrm{Al}_{14} \mathrm{O}_{25}: \mathrm{Eu}^{2+} / \mathrm{Dy}^{3+}$ phosphor. Inserted figure shows the variation of emission intensity with particle size of $\mathrm{Al}_{2} \mathrm{O}_{3}$.

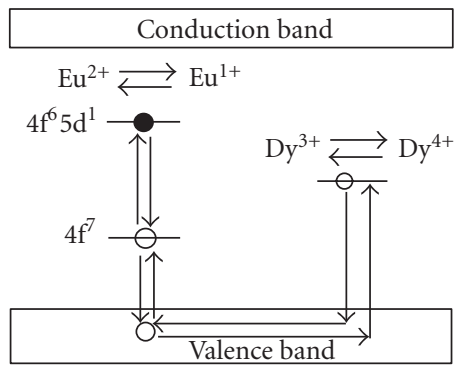

Figure 5: The mechanism of long afterglow of $\mathrm{Sr}_{4} \mathrm{Al}_{14} \mathrm{O}_{25}: \mathrm{Eu}^{2+}$ / $\mathrm{Dy}^{3+}$ phosphor.

of $5 \mathrm{mcd} \cdot \mathrm{m}^{-2}$ was more than 20 hours. The longer afterglow duration of the smaller particles phosphor may be explained as, upon exposure to light source, the direct excitation of $\mathrm{Eu}^{2+}$ due to $4 \mathrm{f}$ to $4 \mathrm{f} 5 \mathrm{~d}$ transition occurs (Figure 5), and a great numbers of holes are generated near the valence band. Some of these free holes are released thermally to the valence band, migrate through the valence band, and captured by the $D y^{3+}$-borate complex $[6,11]$. When the excitation source is removed, the trapped holes are released thermally to the valence band, migrate to the excited $\mathrm{Eu}^{2+}$, and consequently, the recombination takes place, which leads to the long afterglow. So, the long afterglow duration depends on the number of captured holes. The numbers of captured holes, in turn, depend on the concentration of Dy-borate complexes and the trap depth of it. With the decrease of particle size, the blue shift of the trap depth occurs [9] that leads to increase in the afterglow duration. The detailed explanation of the mechanism with other supporting information is under progress.

\section{Conclusions}

Long-afterglow $\mathrm{Sr}_{4} \mathrm{Al}_{14} \mathrm{O}_{25}: \mathrm{Eu}^{2+} / \mathrm{Dy}^{3+}$ phosphor was synthesized by solid phase reaction method using $\alpha$ and $\gamma$ types $\mathrm{Al}_{2} \mathrm{O}_{3}$ of different particle sizes. Though the same $\mathrm{Sr}_{4} \mathrm{Al}_{14} \mathrm{O}_{25}$ 
phase was formed on changing the alumina precursors, quite different structures were observed. When $0.05 \mu \mathrm{m} \gamma-\mathrm{Al}_{2} \mathrm{O}_{3}$ was used, spike-like phosphor particles were observed with minimum particle size, which agglomerated to form a ball-like structure. When $0.1 \mu \mathrm{m} \alpha-\mathrm{Al}_{2} \mathrm{O}_{3}$ was used, bigger particles with the shape of hexagon were observed, while using $1.0 \mu \mathrm{m} \alpha-\mathrm{Al}_{2} \mathrm{O}_{3}$ much bigger but thinner irregular particles were observed, that is, the shape and size of phosphor particles can be controlled by changing the alumina precursor under the experimental conditions. The better phosphorescence intensity and persistency were observed for the phosphor prepared using $0.05 \mu \mathrm{m} \gamma-\mathrm{Al}_{2} \mathrm{O}_{3}$ that might be due to the smaller and regular particles formation.

\section{References}

[1] C. Chang, D. Mao, J. Shen, and C. Feng, "Preparation of long persistent $\mathrm{SrO} \cdot 2 \mathrm{Al}_{2} \mathrm{O}_{3}$ ceramics and their luminescent properties," Journal of Alloys and Compounds, vol. 348, no. 1-2, pp. 224-230, 2003.

[2] T. Aitasalo, J. Hölsä, H. Jungner, M. Lastusaari, and J. Niittykoski, "Mechanisms of persistent luminescence in $\mathrm{Eu}^{2+}$, $\mathrm{RE}^{3+}$ doped alkaline earth aluminates," Journal of Luminescence, vol. 94-95, pp. 59-63, 2001.

[3] R. Zhong, J. Zhang, X. Zhang, S. Lu, and X.-J. Wang, "Red phosphorescence in $\mathrm{Sr}_{4} \mathrm{Al}_{14} \mathrm{O}_{25}: \mathrm{Cr}^{3+}, \mathrm{Eu}^{2+}, \mathrm{Dy}^{3+}$ through persistent energy transfer," Applied Physics Letters, vol. 88, no. 20, Article ID 201916, 3 pages, 2006.

[4] V. Shankar, H. Chander, H. Divi, and P. K. Ghosh, "Long decay luminescent powder and process for preparation thereof," US patent no. 0183807 A1, October 2003.

[5] Y. Lin, Z. Zhang, F. Zhang, Z. Tang, and Q. Chen, "Preparation of the ultrafine $\mathrm{SrAl}_{2} \mathrm{O}_{4}: \mathrm{Eu}$, Dy needle-like phosphor and its optical properties," Materials Chemistry and Physics, vol. 65, no. 1, pp. 103-106, 2000.

[6] A. Nag and T. R. N. Kutty, "Role of $\mathrm{B}_{2} \mathrm{O}_{3}$ on the phase stability and long phosphorescence of $\mathrm{SrAl}_{2} \mathrm{O}_{4}$ : Eu, Dy," Journal of Alloys and Compounds, vol. 354, no. 1-2, pp. 221-231, 2003.

[7] Z.-X. Yuan, C.-K. Chang, D.-L. Mao, and W. Ying, "Effect of composition on the luminescent properties of $\mathrm{Sr}_{4} \mathrm{Al}_{14} \mathrm{O}_{25}: \mathrm{Eu}^{2+}, \mathrm{Dy}^{3+}$ phosphors," Journal of Alloys and Compounds, vol. 377, no. 1-2, pp. 268-271, 2004.

[8] Z. Wu, M. Gong, J. Shi, and Q. Su, "Comparative investigation on synthesis and luminescence of $\mathrm{Sr}_{4} \mathrm{Al}_{14} \mathrm{O}_{25}$ : $\mathrm{Eu}^{2+}$ applied in InGaN LEDs," Journal of Alloys and Compounds, vol. 458, no. 1-2, pp. 134-137, 2008.

[9] Z. Tang, F. Zhang, Z. Zhang, C. Huang, and Y. Lin, "Luminescent properties of $\mathrm{SrAl}_{2} \mathrm{O}_{4}: \mathrm{Eu}$, Dy material prepared by the gel method," Journal of the European Ceramic Society, vol. 20, no. 12, pp. 2129-2132, 2000.

[10] R. M. German, Liquid Phase Sintering, Plenum Press, New York, NY, USA, 1985.

[11] Y. Lin, Z. Tang, and Z. Zhang, "Preparation of long-afterglow $\mathrm{Sr}_{4} \mathrm{Al}_{14} \mathrm{O}_{25}$-based luminescent material and its optical properties," Materials Letters, vol. 51, no. 1, pp. 14-18, 2001. 

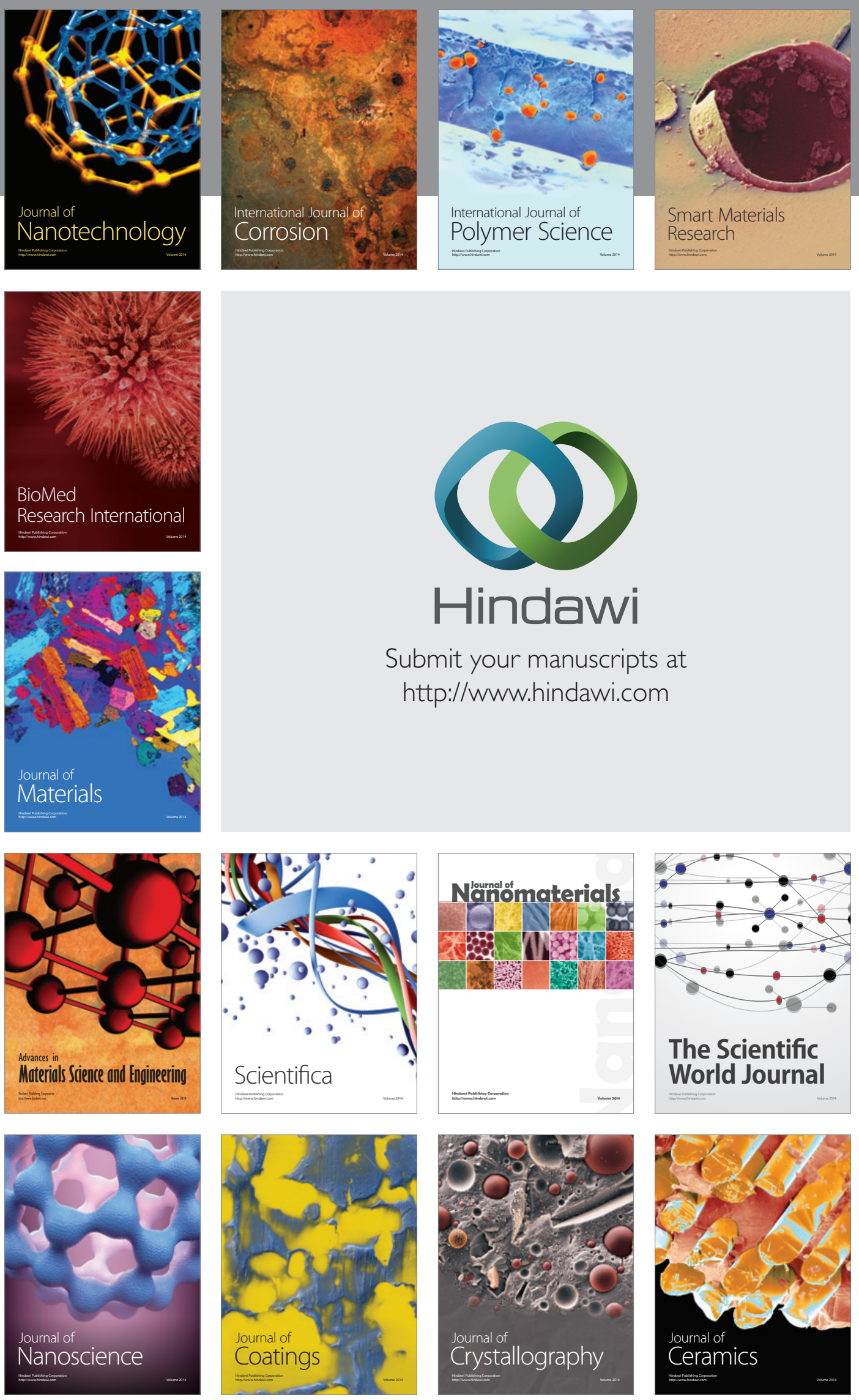

The Scientific World Journal

Submit your manuscripts at

http://www.hindawi.com

\section{World Journal}

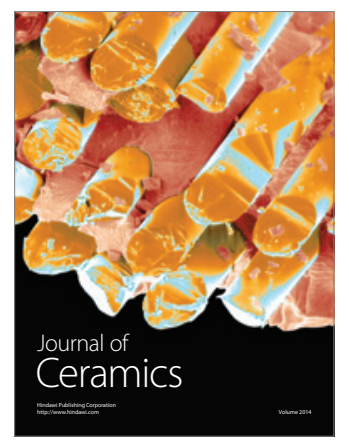

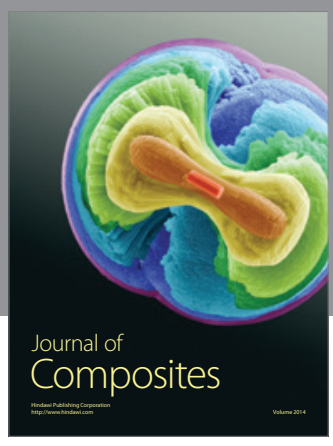
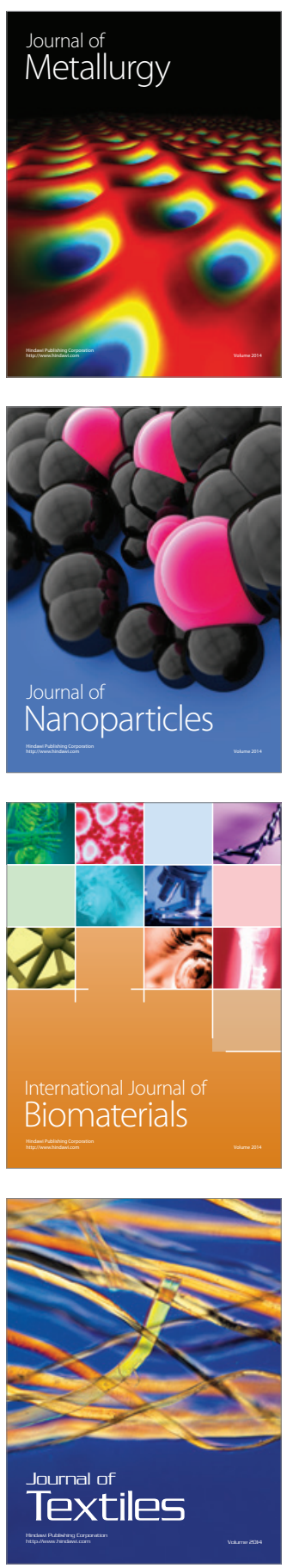